\title{
EVALUATION OF TWO PULPOTOMY AGENTS IN TRAUMATIZED IMMATURE PERMANENT INCISORS
}

\author{
Gihan M. Abuelniel ${ }^{*}$ and Nihal R. Kabel **
}

\begin{abstract}
Aim: To assess the clinical and radiographic outcomes of mineral trioxide aggregate (MTA) and Biodentine as vital pulpotomy materials to maintain the vitality of traumatized immature anterior permanent teeth with pulpal exposure.

Materials and Methods: Fifty vital traumatized immature anterior permanent teeth with exposed pulps were included in the study. Teeth were equally divided and randomly assigned to either a control group (MTA) or the test group (Biodentine). After pulpotomy, pulp stumps were covered with MTA or Biodentine followed by a permanent restoration. Blinded clinical and radiographic evaluations were performed at base line, 6,12 and 18 months according to predetermined clinical and radiographic criteria.
\end{abstract}

Results: No statistically significant differences were observed between MTA and Biodentine for any of the clinical parameters, except for discoloration, which was significantly more prevalent in the MTA group $(\mathrm{p}<0.001)$. No significant statistical difference was observed in the radiographic success between MTA and Biodentine, as evidenced by continued root development presented by an increased prevalence of root formation stage $\mathrm{H}$ in both groups.

Conclusions: Both MTA and Biodentine showed similar clinical and radiographic outcomes when used as vital pulpotomy materials in the treatment of traumatized immature anterior permanent teeth. However, discoloration was significantly more prevalent in the MTA group, and given similar clinical and radiographic outcomes in the two groups, Biodentine should be favored over MTA after pulpotomy for anterior traumatized teeth with pulpal exposure where aesthetics would be of concern.

\section{INTRODUCTION}

The occurrence of dental trauma in permanent teeth is a common event worldwide. Two-thirds of all dental trauma was found among children and adolescents were with the anterior permanent teeth being the most affected ${ }^{[1,2]}$.

Traumatic injuries affecting teeth may result in pulpal and periapical disease. Complicated crown

* Associate Professor of Pediatric Dentistry, Cairo University.

**Associate Professor of Pediatric Dentistry, Misr University of Science and Technology. 
fractures which involve the enamel, dentin and pulp occur in $0.9-13 \%$ of all dental injuries ${ }^{[2,3]}$. (VPT) Vital pulp therapy is the treatment of choice for traumatized immature teeth with pulpal exposure $[5,6]$. VPT promotes root development that leads to apical closure and strengthening of the root structure [7]. If the pulp vitality of a traumatized immature tooth is lost, endodontic treatment will constitute a real challenge. It is difficult to obtain an appropriate apical seal in these teeth by using the conventional obturation methods complicated by thin root walls that make teeth prone to future fractures ${ }^{[8]}$.

Pulp therapy primary objective is to maintain the integrity and health of teeth and their supporting tissues and to preserve pulp vitality, especially in young permanent teeth with immature roots, where the pulp is integral to continue apexogenesis. Favorable crown/ root ratio and thick dentinal walls ensure the long-term survival of a functional permanent tooth. Therefore, pulp preservation is a main goal for young permanent dentition treatment. ${ }^{[9]}$

Recently, vital pulp therapy considered as an effective reasonable alternative to comprehensive endodontic treatment ${ }^{[10]}$. Clinically, VPT includes direct and indirect pulp capping, partial and complete pulpotomy based on the amount of preserved coronal pulp ${ }^{[11]}$. The main goals of these conservative methods are to maintain the normal pulp and remove the contaminated pulpal tissue in order to promote the healing process ${ }^{[9-11]}$. Therefore, immature teeth eventually gain additional benefit from VPT, considering their weak structural nature ${ }^{[11]}$.

Vital pulp therapy has been increasingly considered as a minimal invasive approach for the management of teeth with inflamed pulps compared to the conventional approach of root canal treatment. Among the factors that contributed to this choice are: the high frequency of technically inadequate root fillings and associated apical periodontitis despite new technologies in root canal preparation and filling, the numerous advantages of VPT in terms of preserving tooth structure, maintaining possible proprioceptive defensive mechanisms of the remaining pulp and reducing the probability of tooth fracture. Comparable success rates of VPT and RCT were reported over five years of follow-up ${ }^{[12,13]}$.

$\mathrm{Ca}(\mathrm{OH})_{2}$, was considered the traditional material for VPT for many years. Recently MTA was advocated as an alternative to $\mathrm{Ca}(\mathrm{OH})_{2}$. Its biocompatibility and ability to form cementum attachment has not only been used as a root-end filling material but also has been used in pulpotomy, apexification, direct pulp capping and as a perforation repair material. Some drawbacks were encountered that included handling properties, high cost, long setting time and discoloration ${ }^{[14]}$.

A promising material to overcome the limitations of MTA raised in the dental field called (Biodentine $)^{[15]}$. Biodentine is a calcium silicate cement that was introduced as a 'dentine replacement' material, comparable to MTA in terms of biocompatibility and induction of a calcific barrier. It possessed additional improvement of several properties such as mixing, handling, shorter initial setting time and less coronal discoloration ${ }^{[16]}$.

Limited clinical data were available on the use of Biodentine in VPT; recently only three clinical trials compared Biodentine to MTA as pulp capping materials for cariously exposed teeth with high success rate approaching $100 \%$ at 1-year follow-up in young patients. ${ }^{[16]}$ In a case report, Biodentine was successful in pulpotomy of traumatized permanent incisors at 48 months of follow-up ${ }^{[17,18]}$.

Therefore, the objective of this prospective randomized clinical trial was to assess the clinical and radiographic outcomes of MTA and Biodentine as vital pulpotomy materials to maintain the vitality of traumatized immature anterior permanent teeth. 


\section{MATERIALS AND METHODS}

This study was approved by the institutional ethics and research committee (Cairo university) Number 19118 and registered on clinicaltrial.gov number (NCT03838068). The parents were given all the information regarding the study and informed consent was obtained prior to treatment.

Selection and recruitment of the cases extended from January to October 2016. Thirty-three patients who were referred to the postgraduate pediatric dentistry department clinic for the management of their traumatized permanent incisors teeth were assessed. Only Patients who had traumatic incisors with vital pulp (detected by clinical signs/symptoms) were included according to the following criteria: [18,19]

\section{Inclusion criteria}

- The patient age range 7.5-9 years.

- Noncontributory medical history

- Unilateral/ and or bilateral immature central incisors with complicated trauma (exposure size $\geq 1 \mathrm{~mm}$ )

- The tooth should give positive response to cold testing

- Clinical diagnosis of reversible pulpitis without periapical rarefaction

- The tooth is restorable, mobility was within normal limits

- No signs of pulpal necrosis including sinus tract or swelling

Patients who did not meet the inclusion criteria were excluded from the study. Incisors were assigned randomly in two groups. The MTA group was considered the control group while the Biodentine was the test group.

\section{Sample size calculation:}

The study was a superiority 2 arm trial with a 1:1 allocation ratio. Sample size was calculated based upon the results of Alqaderi et al (2014) ${ }^{[20]}$ who reported the clinical success rate (primary outcome) for $\mathrm{MTA}=90 \%$. Since no relevant literature reported the clinical success rate of Biodentine in permanent teeth of paediatric patients, the success rate was assumed to be $50 \%$. Using alpha level $=0.05$ and $\beta$ level $=0.20$ ( $80 \%$ Power $)$; the minimum estimated sample size will be 20 teeth per group for a total of 40 teeth. To compensate for a drop-out rate of $25 \%$, the number was increased to 25 teeth per group for a total of 50 teeth.

Sample size calculation was performed using IBM $^{\circledR}$ SPSS $^{\circledR}$ Sample Power ${ }^{\circledR}$ Release 3.0.1.

\section{Allocation and Allocation concealment:}

Access cavity prepared teeth were assigned into MTA or Biodentine group using simple randomization $1: 1$ by computer-generated sequence software (random.org). Allocation concealment was performed by the department secretary who obtained the random allocation list and informed the operator about the sequence just before placing the pulpotomy agent. Sequence generation and patient assignment was done by different investigators.

\section{Randomisation and Blinding}

Once the children who fulfilled the inclusion criteria were identified and consented, their teeth were assigned randomly to the two groups. The MTA group was considered the control group while Biodentine was the test group. The study included a total of thirty-three patients with 50 traumatised teeth that presented with crown fractures with pulpal exposure (16 patients with one affected tooth, and 17 with two affected teeth) were randomised into 
the two groups. Children/parents were blinded to the treatment group they were randomised to. The operator who performed all the clinical procedures took no further part in the assessment of outcomes, which were assessed by second blinded clinician, who performed the clinical assessments according to pre-defined criteria. Furthermore, all the radiographic evaluations were performed by a blinded radiologist who evaluated the radiographic outcomes.

\section{Digital Radiographic Examination}

All patients who were clinically eligible for enrolment in the study went through screening preoperative digital periapical radiographic examination to assess the degree of root development/ formation and any dental infections or anomalies that could interfere with the planned treatment.

Digital periapical radiographs were taken using the SOREDEX (SOREDEX Nahkelantie 160, F1-04301 Tuusula, Finland) dental X-ray machine set at $70 \mathrm{kVp}, 8 \mathrm{~mA}$ and 0.08- 0.04 second. The digital radiographs were captured with the periapical parallel technique using 16-inch position indicating device, Rinn XCP holder (XCP, RINN, United Kingdom) and PSP plate size 1 or 2. After radiograph taking, the PSP plate was scanned using the SOREDEX DIGORA Optimal digital intraoral scanner. The software Digora for windows $2.5 \mathrm{Rev}$ 1 Soredex was used for image analysis.

\section{Vital Pulp Therapy}

The treatment was explained to the patients' legal guardians. Upon enrolment, demographic data were recorded.

The study included thirty-three patients having fifty unilateral and / or bilateral traumatized maxillary immature central incisors. Before conducting dental treatment, the affected area was inspected for laceration, mobility, root fracture, soft tissue damage or alveolar bone fracture, if none was detected the treatment was continued as planned.
One pediatric dentist performed all pulpotomies. Local anesthesia was administrated followed by rubber dam isolation; the coronal pulp tissue was excised to the level of the orifice using a diamond bur with water cooling. Hemostasis was achieved by gentle placement of a saline-moistened cotton pellet over amputated pulps for 5 mins. ${ }^{[19,21]}$ Pulp stumps were covered with:

\section{In control group}

White mineral trioxide aggregate (MTA) ProRoot ${ }^{\circledR}$ MTA (Dentsply/ Johnson City, TN, USA) was used as the reference material for comparison and was prepared according to the manufacturer's instructions. A 3-mm-thick layer of MTA was placed over the amputated pulps and was gently adapted to the dentinal walls using a wet cotton pellet deep onto the radicular pulp. A self-cure glass ionomer (GC; GC Corporation, Tokyo, Japan) was placed over the pulpotomy agent before a final restoration of composite resin (Clearfil $^{\mathrm{TM}}$, Kuraray, New York, USA) was done.

\section{In test group}

Calcium silicate based Biodentine ${ }^{\mathrm{TM}}$ (Septodont Ltd., Saint Maur des Fausse's, France) was mixed according to the manufacturer's instructions, and placed over the amputated pulp, followed by a layer of self-cure glass ionomer prior to final restoration with the same technique as in the first group. The intra oral clinical photographs showing the clinical procedures are presented in Figure (1)

\section{Immediate post-operative radiograph (base line)}

After vital pulp therapy (pulpotomy), immediate postoperative digital image was conducted to record base line data. Demirjians et al ${ }^{[22]}$ teeth maturity scores were used to assess the base line stage of root formation/ development.

The maturity scores used during the radiographic assessment of root development were E, F, G and H and described as: 


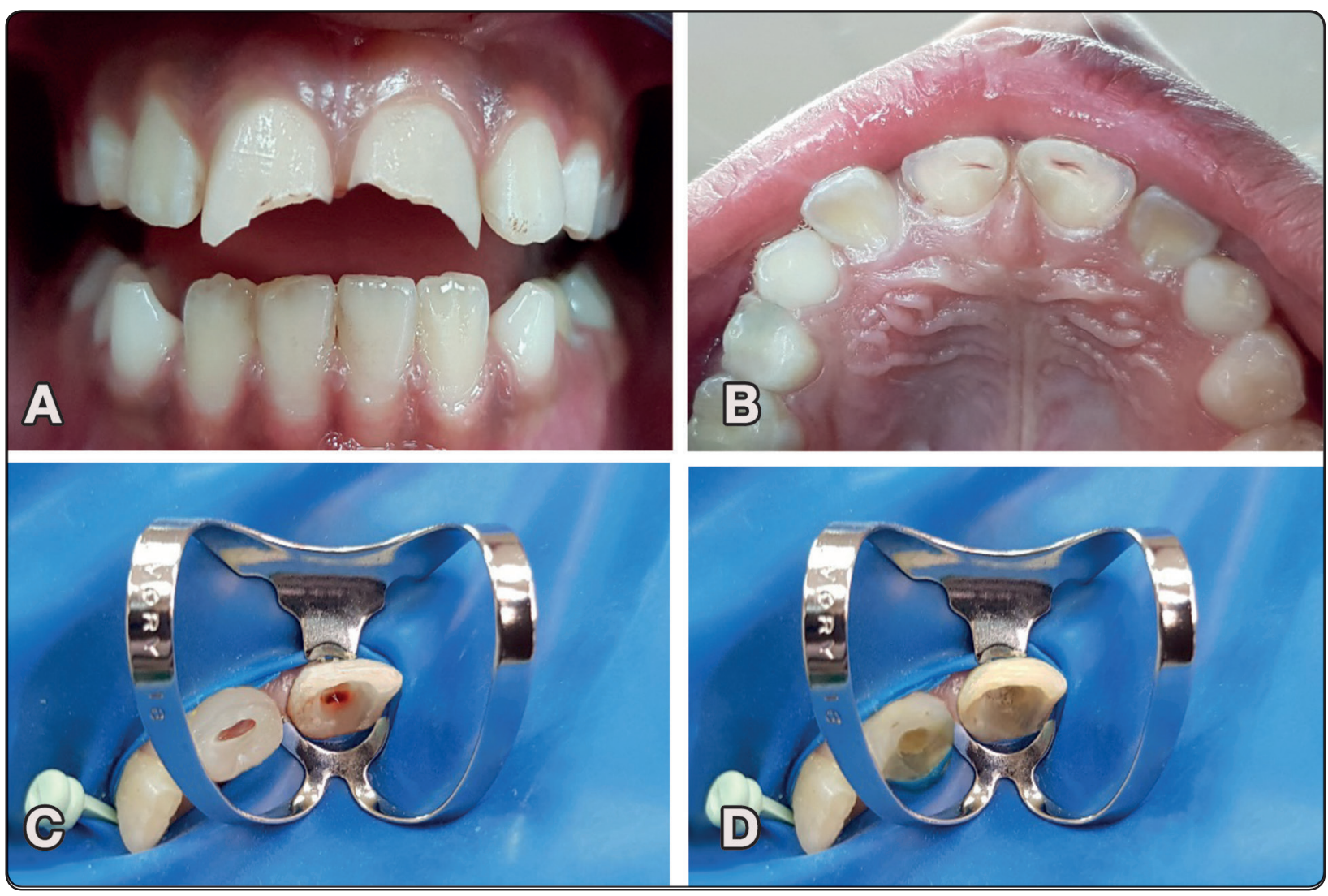

Fig. (1) (A), (B) Pre-operative of traumatized immature central incisors with pulp exposure, (C) Access cavity, (D) pulpotomy with MTA in upper left central and Biodentine in upper right central.

E: a. The walls of the pulp chamber form straight lines, whose continuity is broken by the presence of the pulp horn, which is larger than in the previous stage.

b. the root length is less than the crown height.

F: a. The walls of the pulp chamber form a more or less isosceles triangle. The apex ends in a funnel shape.

b. The root length is equal to or greater than the crown height.

G: The walls of the root canal are parallel, and its apical end is still partially open.

H: a. The apical end of the root canal is completely closed.

b. The periodontal membrane has a uniform width around the root and the apex.

\section{Follow up}

Clinical and radiographic follow-up was carried out at intervals of 6,12 and 18 months. A blinded second paediatric dentist performed clinical examinations according to criteria of clinical success, and a blinded oral radiologist performed radiographic examinations.

The flow of the patients in the study is summarised in Figure 2.

\section{Clinical criteria of success:}

The treatment was clinically considered a success, if the inspected teeth were functional without signs/symptoms of pulp and peri-radicular inflammation/infection as assessed by:

- Absence of pain related to the treated teeth, including patient reported pain or sensitivity to percussion / palpation. 


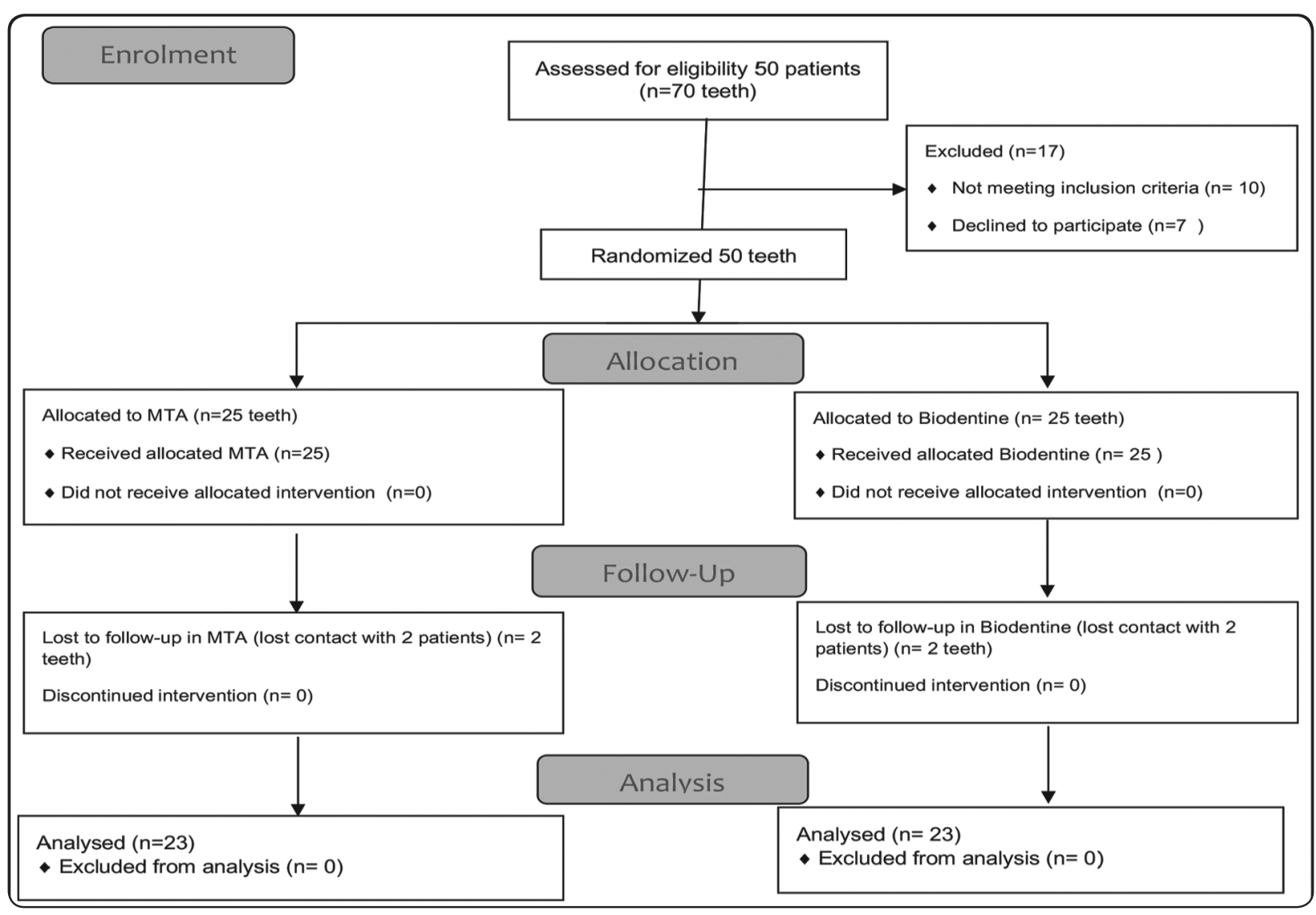

Fig. (2) Flow chart of the trial

- No evidence of swelling of supporting soft tissue or presence of a sinus tract.

- Absence of excessive mobility affecting the treated teeth.

- Absence of discoloration.

\section{Final Digital Radiographic image analysis and radiographic criteria of success}

From the final digital image, the final teeth maturity scores for root development were recorded. Nosrat et al ${ }^{[21]}$ radiographic criteria for treatment success were applied with some modifications to judge the treatment outcome:

- When the progression of root formation/ development- evident radiographically- reached apical closure/ apexogenesis: score H, CR ratio $=2: 1$, apical constriction with or without signs of failure (radicular, interradicular and periradicular rarefaction)-, the treatment was considered complete success.

- When the progression of root formation/development evident radiographically- continued to score $\mathrm{G}, \mathrm{CR}$ ratio=2:1, blunder buss or open apex) -with or without signs of failure (radicular, interradicular and peri-radicular rarefaction)-, the treatment was considered success.

- When the progression of root formation/ development evident radiographically failed to show any progress: score $\mathrm{F}, \mathrm{CR}$ ratio 1:1 or greater and funnel pulp space - with or without signs of failure (radicular, interradicular and peri-radicular rarefaction)-, the treatment was considered failure. 


\section{Statistical Analysis}

Qualitative data were presented as frequencies and percentages. Quantitative data were presented as mean and standard deviation values. Chi-square test and Fisher's Exact test were used for comparisons regarding qualitative data. Student's t-test was used to compare between mean age values in the two groups. Friedman's test was used to study the changes by time within each group. Kaplan-Meier survival curve was constructed to calculate the mean survival estimates of the two groups. Comparison between survival times was performed using Log rank test.

The significance level was set at $\mathrm{P} \leq 0.05$. Statistical analysis was performed with IBM $^{\circledR}$ SPSS $^{\circledR}$ Statistics Version 20 for Windows.

\section{RESULTS}

\section{Demographic data:}

The results showed no statistically significant differences between mean age values and gender distribution in the two groups as presented in table (1).

TABLE (1): Mean, standard deviation (SD), frequencies (n), percentages and results of Student's t-test and Chi-square test for comparisons of demographic data in the two groups

\begin{tabular}{cccc}
\hline & Biodentine & MTA & $P$-value \\
\hline Age (Years) & & & \\
Mean (SD) & $8.4(0.3)$ & $8.3(0.3)$ & 0.851 \\
\hline Gender [n (\%)] & & & \\
Boy & $7(44)$ & $9(52)$ & 0.571 \\
Girl & $9(56)$ & $8(48)$ & \\
\hline
\end{tabular}

*: Significant at $P \leq 0.05$

\section{Clinical evaluation}

Results showing changes within the two groups from baseline are summarized in table (2) and the comparison of the two groups is presented in table (3)

TABLE (2): Descriptive statistics and results of Friedman's test for the changes in clinical success rate within each group at different follow up periods

\begin{tabular}{|c|c|c|c|c|c|c|c|c|c|}
\hline \multirow{2}{*}{ Clinical criteria } & \multirow{2}{*}{ Time } & \multicolumn{2}{|c|}{$\begin{array}{l}\text { Biodentine } \\
(\mathrm{n}=25)\end{array}$} & \multirow{2}{*}{$\begin{array}{c}P \text {-value } \\
\text { (Within group) }\end{array}$} & \multirow{2}{*}{$\begin{array}{c}\text { Effect } \\
\text { size }(w)\end{array}$} & \multicolumn{2}{|c|}{$\begin{array}{c}\text { MTA } \\
(n=25)\end{array}$} & \multirow{2}{*}{$\begin{array}{c}P \text {-value } \\
\text { (Within group) }\end{array}$} & \multirow{2}{*}{$\begin{array}{l}\text { Effect } \\
\text { size }(w)\end{array}$} \\
\hline & & $\mathrm{n}$ & $\%$ & & & $\mathrm{n}$ & $\%$ & & \\
\hline \multirow{4}{*}{$\begin{array}{l}\text { Absence of } \\
\text { pain }\end{array}$} & Base line & 25 & 100 & \multirow{4}{*}{$0.004 *$} & \multirow{4}{*}{0.175} & 25 & 100 & \multirow{4}{*}{$0.007 *$} & \multirow{4}{*}{0.160} \\
\hline & 6 months & 25 & 100 & & & 25 & 100 & & \\
\hline & 12 months & 21 & 84 & & & 22 & 88 & & \\
\hline & 18 months & 20 & 80 & & & 20 & 80 & & \\
\hline \multirow{4}{*}{$\begin{array}{l}\text { Absence of } \\
\text { Swelling }\end{array}$} & Base line & 25 & 100 & \multirow{4}{*}{$0.004 *$} & \multirow{4}{*}{0.175} & 25 & 100 & \multirow{4}{*}{0.080} & \multirow{4}{*}{0.090} \\
\hline & 6 months & 25 & 100 & & & 25 & 100 & & \\
\hline & 12 months & 21 & 84 & & & 22 & 88 & & \\
\hline & 18 months & 20 & 80 & & & 22 & 88 & & \\
\hline \multirow{4}{*}{$\begin{array}{l}\text { Mobility within } \\
\text { normal range }\end{array}$} & Base line & 25 & 100 & \multirow{4}{*}{$0.004 *$} & \multirow{4}{*}{0.175} & 25 & 100 & \multirow{4}{*}{0.080} & \multirow{4}{*}{0.090} \\
\hline & 6 months & 25 & 100 & & & 25 & 100 & & \\
\hline & 12 months & 21 & 84 & & & 22 & 88 & & \\
\hline & 18 months & 20 & 80 & & & 22 & 88 & & \\
\hline \multirow{4}{*}{$\begin{array}{c}\text { Presence of } \\
\text { Discoloration }\end{array}$} & Base line & 0 & 0 & \multirow{4}{*}{0.112} & \multirow{4}{*}{0.080} & 0 & 0 & \multirow{4}{*}{$<0.001 *$} & \multirow{4}{*}{0.735} \\
\hline & 6 months & 0 & 0 & & & 15 & 60 & & \\
\hline & 12 months & 0 & 0 & & & 23 & 92 & & \\
\hline & 18 months & 0 & 0 & & & 22 & 88 & & \\
\hline
\end{tabular}


TABLE (3): Descriptive statistics and results of Fisher's Exact test for comparison between clinical evaluation in the two groups

\begin{tabular}{|c|c|c|c|c|c|c|c|}
\hline \multirow{2}{*}{$\begin{array}{l}\text { Clinical } \\
\text { criteria }\end{array}$} & \multirow[t]{2}{*}{ Time } & \multicolumn{2}{|c|}{$\begin{array}{l}\text { Biodentine } \\
(\mathrm{n}=25)\end{array}$} & \multicolumn{2}{|c|}{$\begin{array}{c}\text { MTA } \\
(\mathrm{n}=25)\end{array}$} & \multirow{2}{*}{$\begin{array}{c}P \text {-value } \\
\text { (Between } \\
\text { groups) }\end{array}$} & \multirow{2}{*}{$\begin{array}{c}\text { Effect size } \\
\text { (v) }\end{array}$} \\
\hline & & $\mathrm{n}$ & $\%$ & $\mathrm{n}$ & $\%$ & & \\
\hline \multirow{10}{*}{ 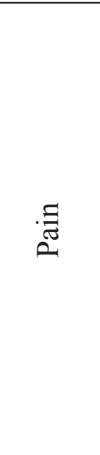 } & Base line & & & & & \multirow{2}{*}{\multicolumn{2}{|c|}{$\mathrm{NC}^{\dagger}$}} \\
\hline & Success & 25 & 100 & 25 & 100 & & \\
\hline & 6 months & & & & & \multicolumn{2}{|c|}{$\mathrm{NC}^{\dagger}$} \\
\hline & $\begin{array}{l}\text { Success } \\
12 \text { months }\end{array}$ & 25 & 100 & 25 & 100 & & \multirow{3}{*}{0.058} \\
\hline & Success & 21 & 84 & 22 & 88 & \multirow[t]{2}{*}{1.000} & \\
\hline & Failure & 4 & 16 & 3 & 12 & & \\
\hline & 18 months & & & & & \multirow{4}{*}{1.000} & \multirow{4}{*}{0.000} \\
\hline & Success & 20 & 80 & 20 & 80 & & \\
\hline & Failure & 3 & 12 & 3 & 12 & & \\
\hline & Drop-out & 2 & 8 & 2 & 8 & & \\
\hline \multirow{11}{*}{ 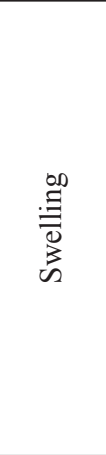 } & Base line & & & & & \multirow{2}{*}{\multicolumn{2}{|c|}{$\mathrm{NC}^{\dagger}$}} \\
\hline & Success & 25 & 100 & 25 & 100 & & \\
\hline & 6 months & & & & & \multirow{2}{*}{\multicolumn{2}{|c|}{$\mathrm{NC}^{\dagger}$}} \\
\hline & Success & 25 & 100 & 25 & 100 & & \\
\hline & 12 months & & & & & \multirow{3}{*}{1.000} & \multirow{3}{*}{0.058} \\
\hline & Success & 21 & 84 & 22 & 88 & & \\
\hline & Failure & 4 & 16 & 3 & 12 & & \\
\hline & 18 months & & & & & \multirow{4}{*}{0.847} & \multirow{4}{*}{0.148} \\
\hline & Success & 20 & 80 & 22 & 88 & & \\
\hline & Failure & 3 & 12 & 1 & 4 & & \\
\hline & Drop-out & 2 & 8 & 2 & 8 & & \\
\hline \multirow{11}{*}{$\begin{array}{l}\stackrel{2}{=} \\
\frac{0}{0} \\
\stackrel{0}{\Sigma}\end{array}$} & Base line & & & & & \multirow{2}{*}{\multicolumn{2}{|c|}{$\mathrm{NC}^{\dagger}$}} \\
\hline & Success & 25 & 100 & 25 & 100 & & \\
\hline & 6 months & & & & & & \\
\hline & Success & 25 & 100 & 25 & 100 & & \\
\hline & 12 months & & & & & & \\
\hline & Success & 21 & 84 & 22 & 88 & 1.000 & 0.058 \\
\hline & Failure & 4 & 16 & 3 & 12 & & \\
\hline & 18 months & & & & & & \\
\hline & Success & 20 & 80 & 22 & 88 & 0847 & 0148 \\
\hline & Failure & 3 & 12 & 1 & 4 & 0.047 & 0.140 \\
\hline & Drop-out & 2 & 8 & 2 & 8 & & \\
\hline & Base line & & & & & & \\
\hline & No discoloration & 25 & 100 & 25 & 100 & & \\
\hline & 6 months & & & & & & \\
\hline 氙 & No discoloration & 25 & 100 & 10 & 40 & $<0.001^{*}$ & 0.655 \\
\hline$\frac{0}{0}$ & Discoloration & 0 & 0 & 15 & 60 & & \\
\hline : & 12 months & & & & & & \\
\hline$\overleftarrow{0}$ & No discoloration & 25 & 100 & 2 & 8 & $<0.001^{*}$ & 0.923 \\
\hline$\stackrel{8}{=}$ & Discoloration & 0 & 0 & 23 & 92 & & \\
\hline 幽 & 18 months & & & & & & \\
\hline 2 & No discoloration & 23 & 92 & 1 & 4 & $<0001 *$ & 0.918 \\
\hline & Discoloration & 0 & 0 & 22 & 88 & $<0.001^{*}$ & 0.918 \\
\hline & Drop-out & 2 & 8 & 2 & 8 & & \\
\hline
\end{tabular}

*: Significant at $P \leq 0.05, N C^{\dagger}$ : Not Computed because the variable is constant 


\section{Pain:}

All treated teeth in both groups remained pain free at 6-month follow-up period. However, at the last follow-up at 18 months significantly fewer teeth remained pain free $(20 / 25$, P-value $=0.004)$ in Biodentine group and $(20 / 25, \mathrm{P}$-value $=0.007)$ in MTA group.

There was no statistically significant difference between presence of pain in the two groups at any of the follow-up periods.

\section{Swelling}

At the 18-month follow-up period, (20 /25, $\mathrm{P}$-value $=0.004)$ in the Biodentine group while $(22 / 25$, P-value $=0.080)$ in the MTA group presented no evidence of swelling. Although this represented a significant decrease from the base line in Biodentine group, there were no significant differences between the two groups at this followup time point $(\mathrm{P}$-value $=0.847)$.

\section{Mobility}

There was a statistically significant decrease in the success rate from baseline when mobility was assessed at 18-month for with number of teeth considered to be within normal limits of mobility being $20(\mathrm{P}$-value $=0.004)$ in the Biodentine group. While, in MTA group no significant change in the success rate regarding mobility was observed with 22 teeth showed no mobility $(\mathrm{P}$-value $=0.080)$.

Although this represented a significant decrease from the base line in Biodentine group, there were no significant differences between the two groups at this follow-up time point $(P$-value $=0.847)$.

\section{Presence of discoloration}

At 6-month follow-up, MTA started to show statistically significant differences in the presence of discoloration that increased with time than Biodentine at 18 -months follow-up point $(P$-value $<0.001)$.

Within each group from baseline, Biodentine group exhibited no statistically significant change in presence of discoloration $(P$-value $=0.112)$. While in MTA group, there was a statistically significant change in presence of discoloration ( $P$-value $<0.001)$. An example for a clinical case is presented in (figure 3)
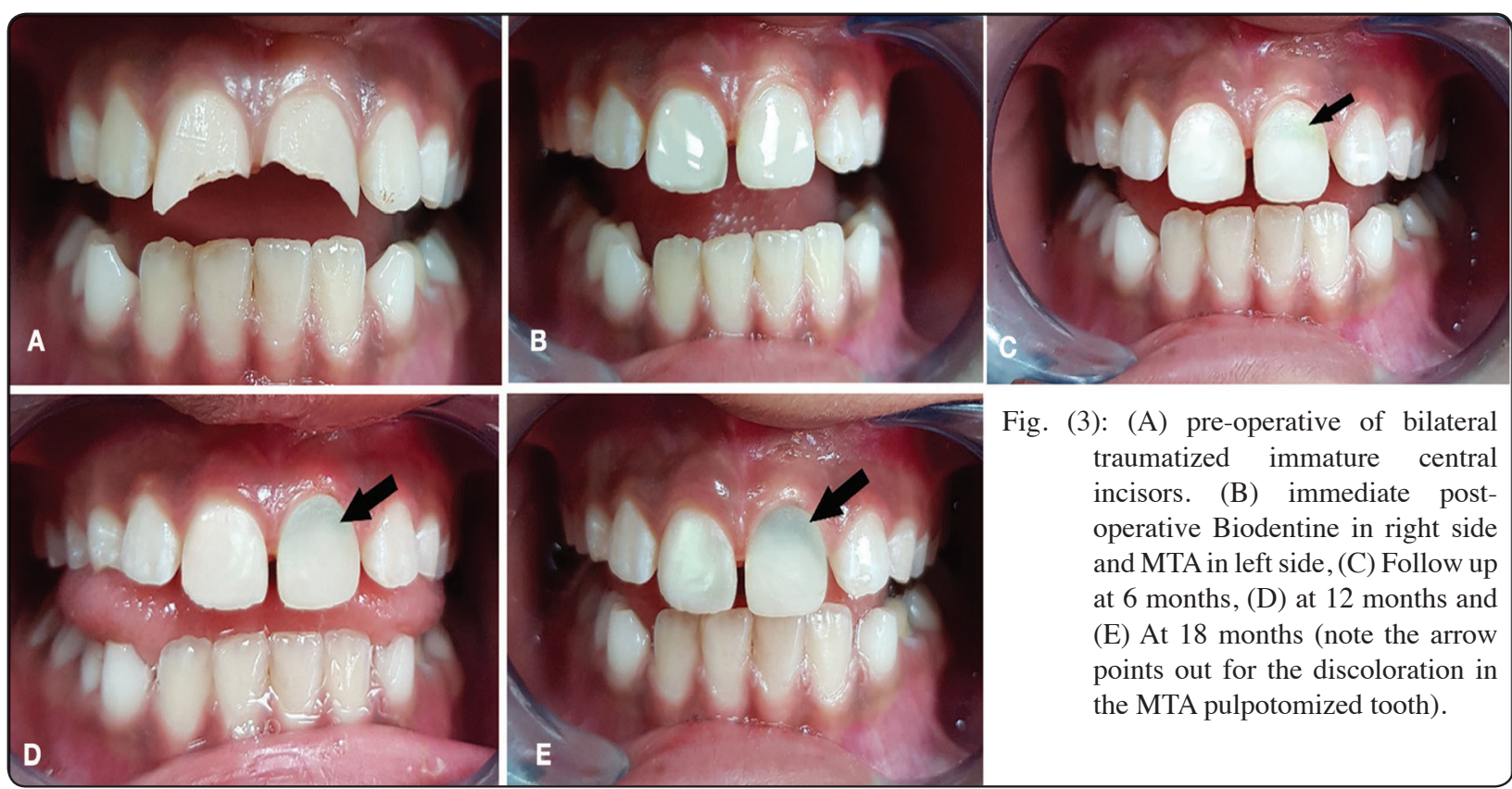

Fig. (3): (A) pre-operative of bilateral traumatized immature central incisors. (B) immediate postoperative Biodentine in right side and MTA in left side, (C) Follow up at 6 months, (D) at 12 months and (E) At 18 months (note the arrow points out for the discoloration in the MTA pulpotomized tooth). 


\section{Survival analysis:}

According to Kaplan-Meier survival analysis, the mean survival time for Biodentine group was 17.04 months with 95\% Confidence Interval (16.2 - 17.9) months. The mean survival time for MTA group was 17.3 months with $95 \%$ Confidence Interval (16.5 18) months. There was no statistically significant difference between survival times of the two groups. Figure (4)

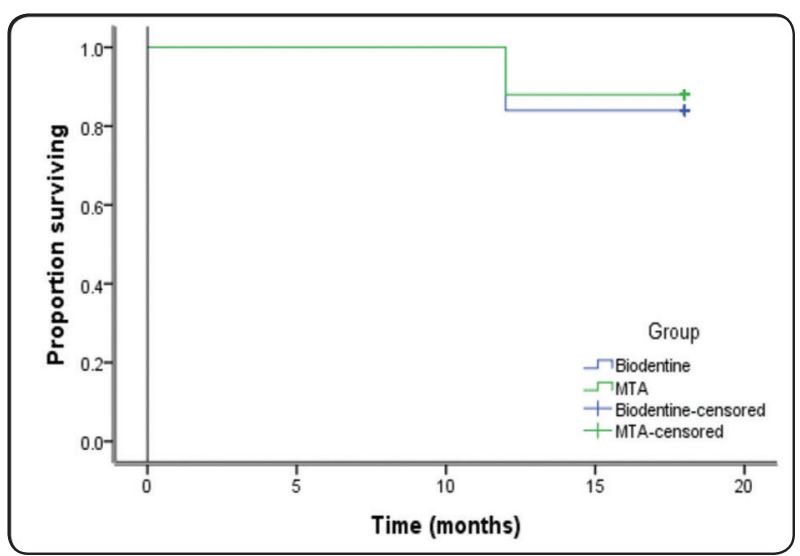

Fig. (4): Kaplan-Meier survival curve for clinical success of the two materials

\section{Radiographic evaluation}

\section{Root formation stage:}

There was a statistically significant increase in continued root development noted at each follow up visit in both the Biodentine ( $\mathrm{p}<0.001$ ), and the MTA groups $(\mathrm{P}<0.001)$, (Table 4$)$. There were no teeth in either group at baseline with stage $\mathrm{H}$ (completed root formation) but at 18 months there were 16 and 17 with stage $\mathrm{H}$ root development in Biodentine and MTA groups respectively.

When the two groups were compared, no statistically significant difference between root formation over the follow-up periods was noted (Table 5).
Figure (5) shows intra-oral radiographs at the different follow-up visits of a pulpotomy performed with Biodentine and MTA as an example of various stages of root development following the treatment.

TABLE (4): Descriptive statistics and results of Friedman's test for the changes in root formation stages within each group at different follow up periods

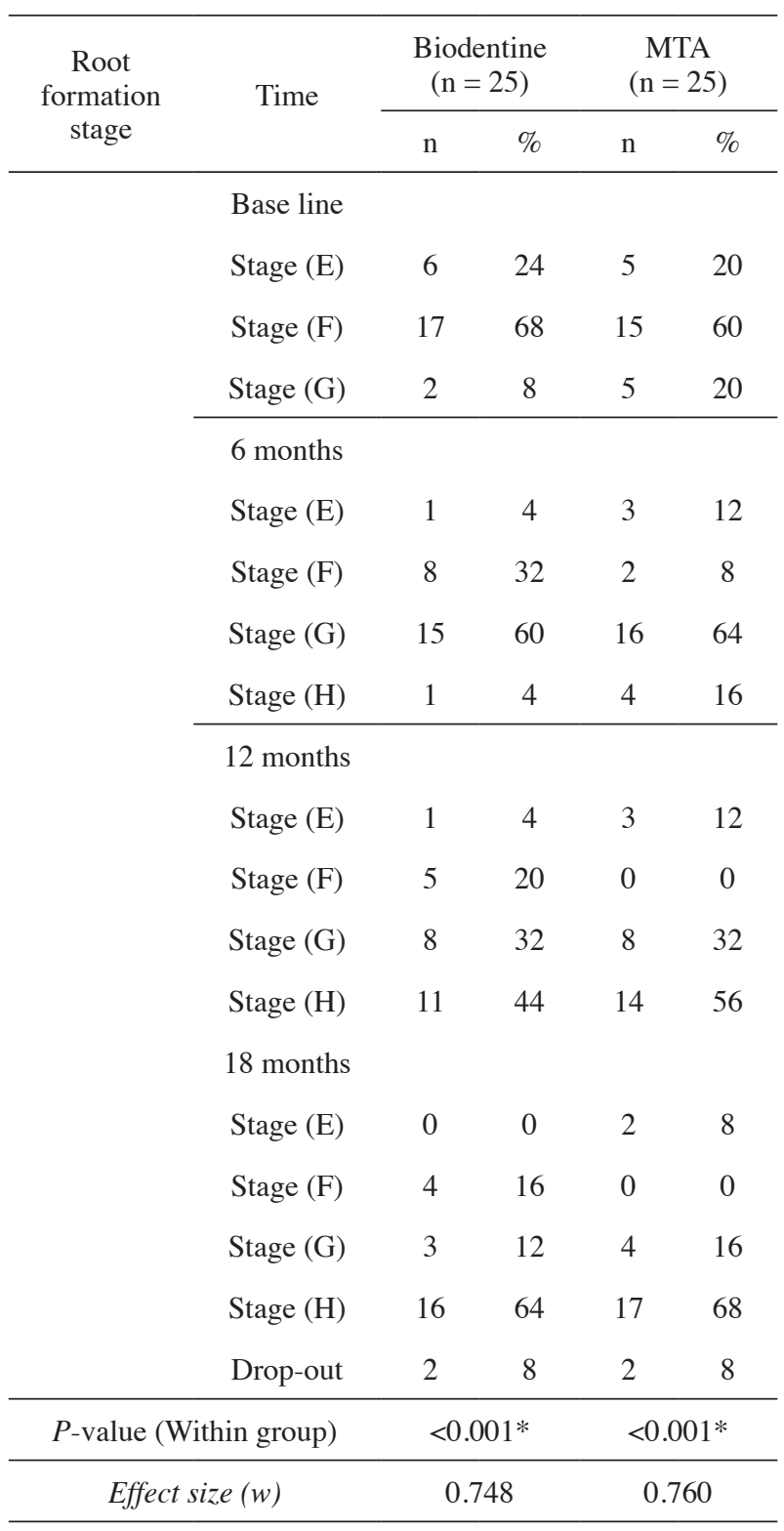

*: Significant at $P \leq 0.05$ 
TABLE (5): Descriptive statistics and results of Fisher's Exact test for comparison between radiographic evaluation in the two groups

\begin{tabular}{|c|c|c|c|c|c|c|c|}
\hline \multirow{2}{*}{$\begin{array}{c}\text { Radiographic } \\
\text { criteria }\end{array}$} & \multirow{2}{*}{ Time } & \multicolumn{2}{|c|}{$\begin{array}{l}\text { Biodentine } \\
(\mathrm{n}=25)\end{array}$} & \multicolumn{2}{|c|}{$\begin{array}{c}\text { MTA } \\
(\mathrm{n}=25)\end{array}$} & \multirow{2}{*}{$\begin{array}{c}P \text {-value (Between } \\
\text { groups) }\end{array}$} & \multirow{2}{*}{$\begin{array}{c}\text { Effect size } \\
(v)\end{array}$} \\
\hline & & $\mathrm{n}$ & $\%$ & $\mathrm{n}$ & $\%$ & & \\
\hline \multirow{20}{*}{ 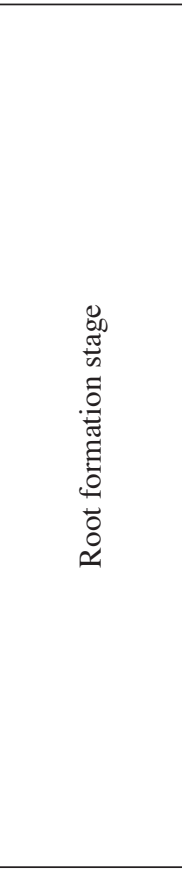 } & Base line & & & & & \multirow{4}{*}{0.598} & \multirow{4}{*}{0.173} \\
\hline & Stage $(\mathrm{E})$ & 6 & 24 & 5 & 20 & & \\
\hline & Stage $(\mathrm{F})$ & 17 & 68 & 15 & 60 & & \\
\hline & Stage $(\mathrm{G})$ & 2 & 8 & 5 & 20 & & \\
\hline & 6 months & & & & & \multirow{5}{*}{0.098} & \multirow{5}{*}{0.359} \\
\hline & Stage $(\mathrm{E})$ & 1 & 4 & 2 & 8 & & \\
\hline & Stage (F) & 8 & 32 & 3 & 12 & & \\
\hline & Stage $(G)$ & 15 & 60 & 16 & 64 & & \\
\hline & Stage $(\mathrm{H})$ & 1 & 4 & 4 & 16 & & \\
\hline & 12 months & & & & & \multirow{5}{*}{0.100} & \multirow{5}{*}{0.357} \\
\hline & Stage $(\mathrm{E})$ & 1 & 4 & 0 & 0 & & \\
\hline & Stage $(\mathrm{F})$ & 5 & 20 & 3 & 12 & & \\
\hline & Stage $(G)$ & 8 & 32 & 8 & 32 & & \\
\hline & Stage $(\mathrm{H})$ & 11 & 44 & 14 & 56 & & \\
\hline & 18 months & & & & & \multirow{6}{*}{0.206} & \multirow{6}{*}{0.351} \\
\hline & Stage $(\mathrm{E})$ & 0 & 0 & 0 & 0 & & \\
\hline & Stage (F) & 3 & 12 & 2 & 8 & & \\
\hline & Stage (G) & 4 & 16 & 4 & 16 & & \\
\hline & Stage $(\mathrm{H})$ & 16 & 64 & 17 & 68 & & \\
\hline & Drop-out & 2 & 8 & 2 & 8 & & \\
\hline
\end{tabular}

\footnotetext{
*: Significant at $P \leq 0.05$
}

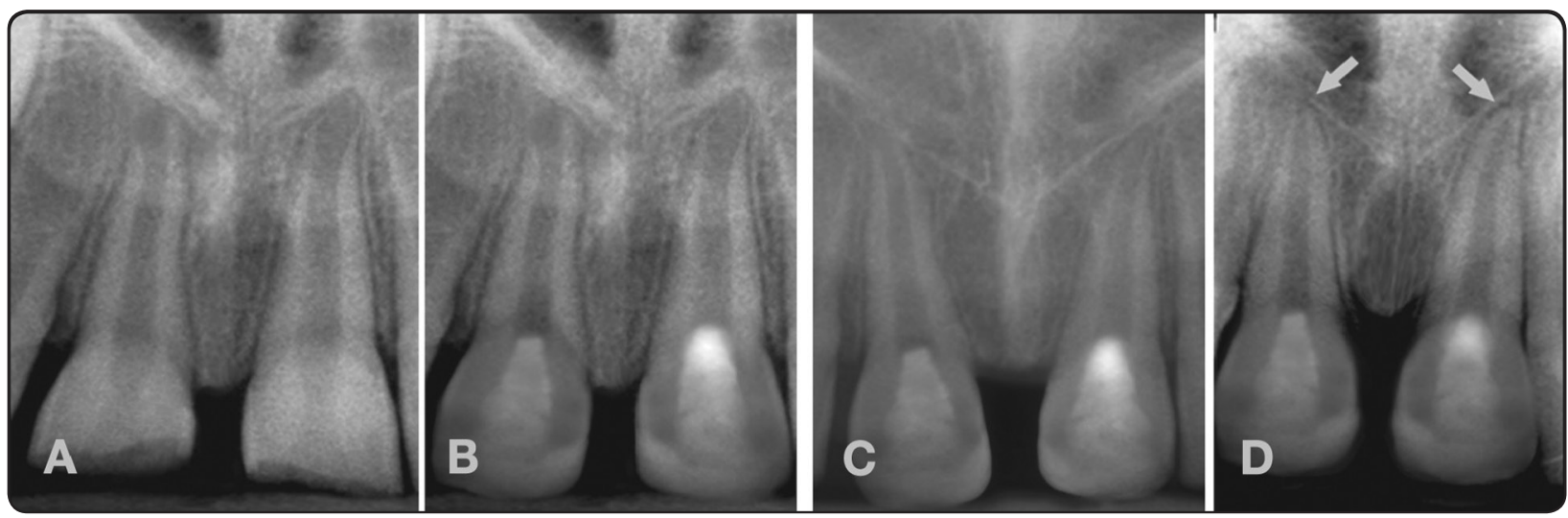

Fig. (5): (A) Intraoral digital periapical images of traumatized immature central incisors preoperatively, (B) immediate postoperative restored with Biodentine in the right side and MTA in the left side (C) follow up at 6 months (D) at 12 months postoperative final digital image Following the Demirjians et al, maturity scoring system for tooth development, the tooth was scored $\mathbf{F}$ immediate postoperative, $\mathbf{G} 6$ months postoperative (note the apical radiolucent area of the dental sac indicating incomplete root apex closure), and was scored $\mathbf{H}$ at 12 postoperative (note the uniform radiolucent outline of the periodontal membrane space around the root apically indicating complete root apex closure and complete root formation achieving $\mathrm{CR}$ ratio $2: 1$ 


\section{DISCUSSION}

Various vital pulp therapy techniques (VPT) considered remarkably important for teeth with complicated crown fracture with vital pulp and open apices ${ }^{[23]}$. When apexogenesis is carried out successfully, healthy pulp promotes physiologic development and formation of root's apex and lateral root walls ${ }^{[24]}$.

In the current study, pulpotomy was carried out because of the expected contamination of the pulp by saliva and oral bacteria as sequalae of complicated crown fractures. It is believed that, during the first 24-48 hours inflammation would be limited to the superficial layer of the pulp. Removal of the contaminated parts of the pulp followed by prevention of any further coronal leakage through the exposed part would promote healing as reported by previous studies. Additionally, other factors such as the time elapsed between the accident and examination and the exposure size contributed to the choice of cervical pulpotomy ${ }^{[25]}$.

Various dental materials have been advocated for use as pulpotomy agents, based on their essential properties such as biocompatibility, sealing ability, healing promotion and antimicrobial efficacy when placed in contact with the inflamed pulp. In the present study, MTA was selected as one of the most commonly used and researched material for such purposes with promising successful clinical outcomes. However, due to certain limitations of MTA mainly discoloration as a result of the additives to improve its radio-opacity, an urge raised for the development of newer materials that may overpower such limitations ${ }^{[26]}$. Biodentine is biocompatible material that primarily formulated using the MTA-based cement technology with improvements in physical properties and handling qualities ${ }^{[27]}$.

The present study was a prospective randomized clinical trial. The patients, clinicians who performed clinical /radiographic follow-up examinations, and the statistician were all blinded to the type of pulpotomy agent used. Analysis of demographic characteristics and distribution of teeth represented no significant differences between the groups. This is essential as it is widely accepted and a requirement of a clinical trial, that randomization and blinding facilitate comparison between study groups and minimize bias and confounding factors ${ }^{[21,28]}$

The difficulty of recalling patients for a clinical study as this one is acknowledged in the literature ${ }^{[29]}$. There was a total of 2 patients having bilaterally traumatized incisors lost to follow-up due to their failure to attend the recall visits. This resulted in an equal number of dropouts from each group. The statistical analysis was performed by intention to treat analysis as the trial was a superiority 2 arm trial with a 1:1 allocation ratio. However, there was no attrition bias since the sample size had already been calculated with a $25 \%$ drop out calculated into account for loss to follow-up.

Both clinical and radiographic examinations are the main parameters to evaluate the success rate of a treatment outcome. This is in accordance with published literature where it has been explained that the main indicators for successful treatment are maintenance of pulp vitality, absence of postoperative clinical signs or symptoms such as pain, swelling or mobility and continued root development as confirmed by radiographic examination. ${ }^{[30]}$

In the present study, no statistically significant differences were recorded for the clinical parameters when the two materials were compared with an exception of discoloration in the MTA group. Despite a statistically significant reduction in clinical success rate, was evident within groups when compared to baseline, these results should be interpreted with caution. The success rate of both materials was in the region of $80 \%$ over an 18 -month period. These teeth remained functional without signs/ symptoms of failure. The results in accordance with various 
researchers who demonstrated decrease in success rates with time. ${ }^{[31,32]}$

Discoloration was an important criterion that have been noticed significantly in the MTA group as early as 6-month, while none of the cases in the Biodentine group reported discoloration throughout the study period. Despite the selection of white MTA and its deep condensation onto radicular pulp, the presence of bismuth oxide in the mixture of MTA was the reason behind discoloration ${ }^{[33,34]}$. On the other hand, the color stability reported in Biodentine throughout the study period was attributed to the replacement of bismuth oxide by zirconium oxide in Biodentine to improve material radiopacity as explained by various researchers. ${ }^{[35,36]}$

The radiographic findings of the current study showed that, from baseline further roots development of the treated teeth occurred and was ascertained by the root maturity score. This is a clear indication of pulp healing and it is not expected that these teeth will become non-vital in the long term. ${ }^{[32]}$

Reported cases of failure both clinically and radiographically could be explained by the fact that, microleakage through the tooth-restoration interface could participate in the final vital pulp therapy outcome. ${ }^{[37]}$ Additionally, other factors that include the presence of microorganisms with subsequent infection, the inflammatory status of the pulp tissue, the size of the pulpal exposure, the amount of crown destruction and the ability to restore a tooth could dramatically affect the treatment outcome of vital pulp therapy. ${ }^{[38-40]}$

\section{CONCLUSIONS}

There was a high success rate with pulpotomy performed in young children in immature traumatized permanent incisors as assessed over an 18-month period, with comparable results when either MTA or Biodentine was used as a vital pulp therapy material over the amputated pulp. Biodentine showed colour stability throughout the evaluation period.

\section{REFERENCES}

1. Bastone EB, Freer TJ, McNamara JR. Epidemiology of dental trauma: a review of the literature. Aust Dent J. 2000; 45:2-9.

2. Canakci V, Akgül HM, Akgül N, Canakci CF. Prevalence and handedness correlates of traumatic injuries to the permanent incisors in 13-17-year-old adolescents in Erzurum, Turkey. Dent Traumatol. 2003; 19:248-254.

3. Tapias MA, Jiménez-García R, Lamas F, Gil AA. Prevalence of traumatic crown fractures to permanent incisors in a childhood population: Móstoles, Spain. Dent Traumatol. 2003; 19:119-122.

4. Witherspoon DE. Vital pulp therapy with new materials: new directions and treatment perspectives-permanent teeth. J Endod. 2008;34: S25-S28.

5. Maryam Forghani, Iman Parisay, Amir Maghsoudlou. Apexogenesis and revascularization treatment procedures for two traumatized immature permanent maxillary incisors: a case report Restor Dent Endod. 2013 Aug; 38(3): 178-181.

6. Asgary S, Eghbal MJ, Fazlyab M, Baghban AA, Ghoddusi J. Five-year results of vital pulp therapy in permanent molars with irreversible pulpitis: a non-inferiority multicenter randomized clinical trial. Clinical Oral Investigations .2015; 19, 335-41.

7. Aguilar P, Linsuwanont P. Vital pulp therapy in vital permanent teeth with cariously exposed pulp: a systematic review. Journal of Endodontics. 2011; 37, 581-7.

8. Qudeimat MA, Alyahya A, Hasan AA. Mineral trioxide aggregate pulpotomy for permanent molars with clinical signs indicative of irreversible pulpitis: a preliminary study. International Endodontic Journal. 2017;50, 126-34.

9. Taha NA, Khazali MA. Partial pulpotomy in mature permanent teeth with clinical signs indicative of irreversible pulpitis: a randomized clinical trial. Journal of Endodontics.2017; 43, 1417-21.

10. Tomson PL, Lumely PJ, Smith AJ, Cooper PR. Growth factor release from dentine matrix by pulp capping agents promotes pulp tissue repair-associated events. International Endodontic Journal. 2017; 50, 281-92.

11. Vallés M, Roig M, Duran-Sindreu F, Martínez S, Mercadé M. Color stability of teeth restored with biodentine: A 6-month in vitro study. Journal of Endodontics .2015;41, 1157-60.

12. Stangvaltaite L, Schwendicke F, Holmgren C et al. Management of pulps exposed during carious tissue removal in adults: a multi-national questionnaire-based survey. Clinical Oral Investigations.2017; 21, 2303-9. 
13. Parirokh M, Torabinejad M, Dummer PMH. Mineral trioxide aggregate and other bioactive endodontic cements: an updated overview - part I: vital pulp therapy. International Endodontic Journal.2018;51, 177-205.

14. Van der Veken D, Curvers F, Fieuws S, Lambrechts P. Prevalence of apical periodontitis and root filled teeth in a Belgian subpopulation found on CBCT images. International Endodontic Journal.2017;50, 317-29.

15. Wolters WJ, Duncan HF, Tomson PL et al. Minimally invasive endodontics: a new diagnostic system for assessing pulpitis and subsequent treatment needs. International Endodontic Journal.2017; 50, 825-9.

16. Katge FA, Patil DP. Comparative analysis of 2 calcium silicate-based cements (Biodentine and Mineral Trioxide Aggregate) as direct pulp-capping agent in young permanent molars: a split mouth study. Journal of Endodontics.2017; 43, 507-13.

17. Linu S, Lekshmi MS, Varunkumar VS, Sam Joseph VG. Treatment outcome following direct pulp capping using bioceramic materials in mature permanent teeth with carious exposure: a pilot retrospective study. Journal of Endodontics.2017; 43, 1635-9.

18. Taha N A, Abdelkhader S.Z. Outcome of full pulpotomy using Biodentine in adult patients with symptoms indicative of irreversible pulpitis: international endodontic journal.2018; 51 (8),819-828.

19. Bilge Gülsüm, Elif YAŞA, Duygu YILDIZELİ. Apexogenesis Of Traumatized Permanent Incisors with or without Tooth Fragment. J Dent Fac Atatürk Uni. 2015; 12, 1-7.

20. Alqaderi HE, Al-Mutawa SA, Qudeimat MA. MTA pulpotomy as an alternative to root canal treatment in children's permanent teeth in a dental public health setting. J Dent 2014 Nov; 42(11)1390-5.

21. Nosrat A, Seifi A, Asgary S. Pulpotomy in caries-exposed immature permanent molars using calcium-enriched mixture cement or mineral trioxide aggregate: a randomized clinical trial. Int J Pediatric Dentistry 2013; 23: 56-63

22. Demirjian A, Goldstein H and tanner J M: a new system of Dental Age Assessment. Human Biology 1973,45: 2,211.

23. Nosrat A, Asgary S. Apexogenesis treatment with a new endodontic cement: a case report. J Endodontics 2010; 36:912-4.

24. Belobrov I, Weis MV, Parashos P. Conservative treatment of a cervical horizontal root fracture and a complicated crown fracture: a case report. Aust Dent J 2008; 53:260-4.

25. Cvek M, Cleaton-Jones PE, Austin JC, Andreasen JO. Pulp reactions to exposure after experimental crown fractures or grinding in adult monkeys. J Endod 1982;8: 391-7.
26. Ng F. K and Messer L. B., "Mineral trioxide aggregate as a pulpotomy medicament: a narrative review," European Archives of Paediatric Dentistry, vol.9, no.1, pp.4-11,2008.

27. Camilleri J, "Investigation of Biodentine as dentine replacement material," Journal of Dentistry, vol.41, no.7, pp.600-610, 2013.

28. Nusair. K.M.B, Qudeimat. M.A. A Prospective clinical study of mineral trioxide aggregate for partial pulpotomy in cariously exposed permanent teeth. J Endod.2006;32(8):731-735.

29. Ward J. Vital pulp therapy in cariously exposed permanent teeth and its limitations. Aust Endod J. 2002; 28:29-37.

30. Martens L, Rajasekharan S, Cauwels R: Pulp management after traumatic injuries with a tricalcium silicate-based cement (BiodentineTM): a report of two cases, up to 48 months follow-up. Eur Arch Paediatr Dent .2015; 16:491-496.

31. Cohenca N, Paranjpe A, Berg J. Vital pulp therapy. Dent Clin North Am. 2013; 57:59-73.

32. Dammaschke T, Leidinger J, Schäfer E. Long-term evaluation of direct pulp capping - Treatment outcomes over an average period of 6.1 years. Clin Oral Investig. 2010; 14:559-67.

33. Felman D, Parashos P. Coronal tooth discoloration and white mineral trioxide aggregate. J Endod. 2013; 39:484-7.

34. Marciano MA, Costa RM, Camilleri J, Mondelli RF, Guimarães BM, Duarte MA. Assessment of color stability of white mineral trioxide aggregate angelus and bismuth oxide in contact with tooth structure. J Endod 2014; 40:1235-40.

35. Camilleri J. Staining Potential of Neo MTA Plus, MTA Plus, and Biodentine Used for Pulpotomy Procedures. J Endod,2015 Jul;41(7):1139-45.

36. Kohli MR, Yamaguchi M, Setzer FC, Karabucak B. Spectrophotometric analysis of coronal tooth discoloration induced by various bioceramic cements and other endodontic materials. J Endod 2015; 41:1862-6.

37. Murray PE, About I, Lumley PJ, Franquin JC, Remusat M, Smith AJ. Cavity remaining dentin thickness and pulpal activity. Am J Dent 2002;15(1):41-6.

38. Akhlaghi. N, Khademi. A. Outcomes of vital pulp therapy in permanent teeth based on review of the literature. Dent Res J 2015; 12(5):406-417.

39. Nair P, Duncan H, Pitt Ford T, Luder H. Histological, ultrastructural and quantitative investigations on the response of healthy human pulps to experimental capping with mineral trioxide aggregate: a randomized controlled trial. Int Endod J 2008; 41: 128-150.

40. Aguilar P, Linsuwanont P. Vital pulp therapy in vital permanent teeth with cariously exposed pulp: A systematic review. J Endod. 2011; 37:581-7. 